\title{
Classification of Software Contracts: Analysis of the European Union and the American Legal Systems
}

\author{
Kujo Elias McDave \\ Dean, Faculty of Law, Pentecost University, Ghana. \\ E-mail: mcdaveap@yahoo.com,emkujo@pentvars.edu.gh
}

\begin{abstract}
We live in a time when the use of technology is simply a way of life. All ages and sexes have access to the software; younger audiences use gaming software and music software apps, while older audiences have access to much more software such as computer operating systems. The classification of software for contract purposes affects the choice of law, remedies, and defences that parties can exercise to an agreement. This paper seeks to provide a clear insight into how software contracts are classified in two different legislative regimes, the European Union and the United States of America, to add to the relatively scarce literature on the importance of classification of software for commercial contracting law.The paper concludes that emerging economies such as China have now entered the software arena, indicating a clear need to unify the current laws that regulate software contracts.
\end{abstract}

Keywords: Software Contract, Classification, European Union, United States of America.

DOI: $10.7176 / \mathrm{JLPG} / 118-06$

Publication date: February $28^{\text {th }} 2022$

\section{Introduction.}

The significance of software trade in today's modern world can only be understated. ${ }^{1}$ It is recorded that a number of the top profits earning companies in the world happen to be software companies. Many of the most inventive companies have frequently been acknowledged to be software companies. It therefore comes to no surprise that many of these prominent market forecasters foresee a US \$100 billion market in the gaming industry, that is, software-based video games, alone by the end of $2018 .^{2}$

The E.U currently produces at least $33 \%$ of the world's software, and has been active in producing contracting rules for software. ${ }^{3}$ While the U.S is home to major software producers such as Microsoft and Oracle. These two jurisdictions offer the best environment to get to the bottom of where software lies for the purpose of classification under commercial contract law. The classification of a software contracts is still debatable within a number of legal systems and this is most likely because of its distinctive nature in terms of a transferee's limited authority as well as the non- tangibility of the computer software. In the realm of transnational commercial law, software transactions are quite important.

For example, the general consensus in EU Member States is that the sale of software on a disk is the sale of a good and the Member States also recognize that custom design software is a service. The issue that arises is the classification of electronic software. This is because E.U Member States have taken different positions on the issue of electronic software and have even used different reasoning to reach the same conclusion.

While parties to an international commercial contract are free to choose which law will apply to their contract, most "software trading nations", with the exception of India, brazil, and the UK, are now signatories to the United Nations Conventions on Contracts for the International Sale of Goods (CISG). ${ }^{4}$ As the software industry continues to grow, this issue has continued to plague it. There is still no proper classification for software contracts.

In addition, the United States and the European Union shadow completely opposed approaches to consumer protection in software licensing. Europe's harmonized system of procedural and substantive law has its origins in the unifying principles of the 1957 Rome Treaty. While the E.U bears in mind harmonizing some rules for an internet transaction, the E. U's position on electronically delivered software and contract law is unclear. The question therefore arises, and has often been the subject of intense debate ${ }^{5}$ : can a software contract be regarded as a contract of sale of goods or services in the context of international sales law?

Distinguishing a product contract as some kind of contract may have grave lawful outcomes. Globally, classifying software contracts as a good contract will have it classified under the General Agreement on Tariffs

\footnotetext{
${ }^{1}$ Rustad. M. L \& M.V. Onufrio. M.V. (2010). The Exportability of the Principles of Software: Lost in Translation? 2 HASTINGS SCI. AND TECH. L.J.

${ }^{2}$ DFC Intelligence Forecasts Global Video Game Software Industry to Reach $\$ 100$ Billion in 2018, DFC INTELLIGENCE (November 6, 2018), http://www.dfcint.com/wp/dfcintelligence-forecasts-global-video-game-software-industry-to-reach-100-billion-in-2018/. Last Visited January 8, 2022.

${ }^{3}$ U.S. Industry \&Trade Outlook 1999, The McGraw-Hill Companies, US Department of Commerce/ International Trade Administration, Chapter, 28.

${ }^{4}$ CISG: TABLE OF CONTRACTING STATES, http://www.cisg.law.pace.edu/cisg/countries/cntries.html (last visited, Jan. 8, 2022)

${ }^{5}$ S. Green \& D. Saidov, Software as Goods, J. OF BUS. L. 161 (2007).
} 
and Trade with Goods (GATT) while grouping it as a service contract will make it fall under the General Agreement on Trade Service (GATS). Besides, the United Nations Convention on the International Sale of Goods contracts and, consequently, arrangement of a product contract is important for deciding its relevance. Nationally, the utilization of certain national contracting rules, e.g., implied terms, consumer protection, and so on, may rely upon the kind of agreement. While the law gives guarantees with regards to the nature of goods sold, there are no such guarantees with regards to software contracts, under which governments are provided with sensible care and skill.

This paper seeks to find out whether a software contract can be classified under the traditional method of classification adopted in the American legal system or as the European Union's position and the factors that have contributed to this position. In addition, this paper will seek to understand whether this lack of coherence on its definition has given rise to a new type of contract governed by common law rules or European Union.

\section{Software Contract and the Law.}

Software, also referred to as computer programs are a set of instructions that, when combined with an appropriate machine-readable form, are able to cause a computer to perform specific functions. Software may also be defined simply as instructions that are capable of being accomplished or completed by a computer. Therefore, a computer program works similarly to a cooking recipe, in that it has a sequence of instructions to be fulfilled by a computer. However, A software contract is basically a legally binding covenant between an owner of a software product and a buyer. This is a contract that enables the buyer to use the software legally.

Software licenses are legally binding agreements that serve as guiding principles for the use and the dissemination of software products. A software license will stereotypically provide the end user the legal rights to one or more copies of the software without going against the copyrights to such software. A typical license agreement will define the responsibilities of the parties as well as imposing limitations and boundaries over how the software can be able to be used. Terms and conditions of such agreements contain conditions such as fair use, the limitations of liability, warranties and disclaimers as well as protections in the event that software or its use infringes on other party's intellectual property rights.

Software is a creation of technology. Therefore, within the legal atmosphere, it is heavily governed by Intellectual Property Law. The relationship amid software and intellectual property lies in copyright and patent law respectively, mainly due to its function and tangibility. However, for the purpose of this study, the relationship between software and commercial law is what will be taken into consideration. Most commercial software today is sold under different types of software licensing agreements. Therefore, the relationship between software and the law means that the laws relevant to its use and software itself. This study takes into consideration the international and domestic perspectives respectively, since software sales trade is international and the figures that are available online are able to be viewed worldwide.

\section{Classification of Software Contracts under the E.U legal system.}

\subsection{Classification Based on Tangibility and Intangibility}

Within the European Union, software is considered a digital product, hence considered intangible and the term can be traced to a number of Directives. The CISG, which regulates international commercial sales was the main model for the European Consumer Sales Directive (1999/44/EC), therefore it generally parallels the European Sales Directive. The Consumer Sales Directive (1999/44/EC) gives a definition of consumer goods being a tangible portable element therefore, excludes intangibles such as digital products.

Therefore, this means that a software program that is not transferred on a medium or if such software is only available through electronic means of communication such as through downloading, it would not be protected under the Consumer Sales Directive. In addition, the Consumer Rights Directive of 2011 (2011/83/EU) already provides special rules for 'digital content' together by means of the repealed Distance Selling Directive which refers to digital content regardless of the form of supply by defining it as data that is produced as well as delivered in a digital manner regardless of if it is retrieved via downloads or stream services, from a touchable medium or through supplementary ways.

Both of these legislative approaches draw a clear distinction over the supply of a digital product in an intangible form. On one hand, digital products, which are not provided via touchable mediums are completely omitted from the Consumer Sales Directive scope. On the other hand, the Consumer Rights Directive $(2011 / 83 / \mathrm{EU})$ generally includes digital products, which are generally considered intangible, but, are supplied on a tangible medium, both Directives consider and treat them as goods.

Nevertheless, the Consumer Sales Directive still uses the criteria of tangibility and intangibility to introduce a new contract type for its purposes. Through recital 19, it is understood that agreements targeted towards digital content, that are not supplied upon any physical medium, ought not to be categorized under a sale contract or under a service agreement.

However, if such digital content gets provided via physical mediums, for example a diskette, it ought to be 
categorized goods in the definition given under Consumer Sales Directive. This proves constant reliability on tangibility, which is already also recognized as the crucial factor for digital products in the context of exhaustion in the EU's Copyright law. Following this approach, the Directive uses the criterion of tangibility repeatedly during treatment of 'digital content' regarding rights concerning withdrawal, ${ }^{1}$ information for consumers, ${ }^{2}$ and the provisions concerning the allocation of risks under Article 18 and 20 respectively.

In a bid to show that the EU has decreased its reliance on tangibility for classification of contracts, the Online Sales Directive ${ }^{3}$ as well as Digital Content Directive were proposed under European Commission in December 2015. Reasons for this was to contribute to the Digital Single Market Strategy. ${ }^{4}$ Online Sales Directive has since been amended by the European Commission applies to all sales without restriction to online sales. ${ }^{5}$ The Digital Content Directive concerns the supply of digital content. In general, both proposals aim at the full harmonization of specific rules on conformity and contractual remedies in cases concerning nonconformity with consumer contractual agreements.

The scope of these two proposed Directives is the clear separation between the governing objects of the two legislative instruments, digital content and services ${ }^{6}$ on one side and goods on another side.

The Digital Content Directive explicitly claims that it applies to tangible objects, ${ }^{7}$ by stating that the Directive is to be geared towards long lasting medium integrating digital content in the event that such longlasting medium had been explicitly used to transfer digital content. ${ }^{8}$ To support the new approach, Article 20 (1) of the Digital Content Directive in its definition of 'consumer goods' introduces the exclusion of a tangible 'carrier medium' from the regulatory power given to the Consumer Sales Directive.

This exclusion of such a durable carrier medium within the Digital Content Directive, nevertheless, is restricted, because its provisions concerning the supply are only applicable on the transfer via download. The European Council even proposed to explicitly refer to and include a physical medium that would be incorporated digital content in a manner that such physical mediums serve solely as a transferor for digital content. ${ }^{9}$ Additionally, The European Council proposed to consolidate this dividing line by additionally excluding embedded digital content ${ }^{10}$ from the scope of the directive in Article 3(3a). ${ }^{11}$

General Rapporteurs Gebhardt and Voss made their report on these Directives for the European Parliament but did not give any reference to the criterion of tangibility. However, it proposed to further broaden the scope of the provisions and include "embedded digital content and services" ${ }^{12}$. However, there was a proposal to introduce restriction that the directive shall only be applicable with regards to respect to the affixed digital content or digital services, and not in regards to additional features of these types of goods. ${ }^{13}$

Although this approach is often based on the consideration of a transfer on a tangible medium, it was also adopted for the supply via download by some Member States. ${ }^{14}$ Most importantly, there are also some member states that consider the question of tangibility completely unnecessary because they acknowledge intangibles like digital products to be the object of a sales contract or at least to qualify for the application of sale provisions on defective goods. Therefore, in some Member States, the permanent supply via download of intangibles would facilitate the application of sales provisions. ${ }^{15}$

\subsection{Classification as a Service Transaction}

In the matter concerning service contracts, the EU acquis communautaire ${ }^{16}$ is not strongly developed as

\footnotetext{
${ }^{1}$ Article 9 (2) c, it provides different obligations of the consumer in the event of withdrawal in Article 14 (4) b and sets a special exclusion of the right of withdrawal Article $16 \mathrm{~m}$ of the Consumer Rights Directive 2011/83/EU.

${ }^{2}$ Article 5 (2) and Article 6 (2)

${ }^{3}$ Online Sales Directive, COM (2015) 635 final

${ }^{4}$ COM (2015) 192 final

${ }^{5}$ Online Sales Directive, COM (2015) 635 final.

${ }^{6}$ The original draft of the European Commission included digital services in the definition of 'digital content' in Article 2 let. 1 COM (2015) 634 final.

${ }^{7}$ Schmidt-Kessel/Erler/Grimm/Kramme, Die Richtlinienvorschläge der Kommission zu Digitalen Inhalten und Online-Handel - Teil 1, in GPR 2016, p.2

${ }^{8}$ Directive on the Supply of Digital Content, COM (2015) 634 final.

${ }^{9}$ Sein. K. (2017). What Rules Should Apply to Smart Consumer Goods? Goods with Embedded Digital Content in the Borderland Between the Digital Content Directive and 'Normal' Contract Law, 8 JIPITEC 96 para 1.

${ }^{10}$ Ibid

${ }^{11}$ General Approach of the European Council (9901/17 ADD 1, 2015/0287 (COD)).

12 Article 2 (1b) of the general report of Gebhardt and Voss of the European Parliament (COM (2015)0634 - C8- 0394/2015 2015/0287(COD))

${ }^{13}$ Proposed amendment to Article 3 (3) in the general report of Gebhardt and Voss of the European Parliament (COM (2015)0634 C80394/2015 - 2015/0287(COD)).

${ }^{14}$ BGH, NJW 2007, 2394 (Germany), 64 C.S.J. Luxembourg, 5 February 2003, DAOR, 2003/67, p. 47 (Luxemburg), Software Incubator Ltd v Computer Associates Ltd [2016] EWHC 1587 (QB) (01 July 2016) (GB), Dutch Supreme Court ECLI:NL:HR:2012:BV1301 (Netherlands). 15453 (1) BGB in Germany

${ }^{16}$ The cumulative body of EU legislation consisting of primary (EU treaties), secondary (directives and regulations) legislation and the case law of the CJEU, available https://ec.europa.eu/agriculture/glossary/acquiscommunautaire en de. Accessed on 9th Jan 2022.
} 
compared to the EU's sales law. ${ }^{1}$ For example, the EU Service Directive $(2006 / 123 /)^{2}$, according to recital 90 , does not unequivocally govern or make an effect on contract relationship amid providers as well as clients in need of services. ${ }^{3}$ In addition, in decisions considering the fundamental freedoms, the Court of Justice of the European Union (CJEU) seems to classify intangible items as a service by Article 56 of Treaty on the Functioning of the European Union (TFEU).

However, this assumption has not been, at least expressly, reflected in either the consumer acquis or in the Services Directive 2006/123/EC. ${ }^{4}$ Generally, the EU's private law is characterized by the core elements of goods and services, having their origins in the EU law fundamental freedoms and their institute of services as the general subsidiary under category 57 of the Treaty on the Functioning of the European Union (TFEU). ${ }^{5}$ As mentioned, the Consumer Sales Directive only governs the sales for a purchasers goods and must be generally considered separately from the subsidiary category of services.

However, a contractual agreement for distribution of consumer goods intended for industrial or production under Article 1(4) as well as contractual obligations providing for installation of such properties linked to the sale under Article 2 (5) may be provided protection under the Consumer Sales Directive, even though they have an element service. With regard to software which contains elements of service, the consumer sales law provisions provided by Article 1(4) of the Consumer Sales Directive applies as long as the service.

Concerning the differences between services and the supply of digital content by Consumer Rights Directive, providing an expansive meaning for digital content as data that is created as well as when delivered as digital form may also include supply of digital products through the access of cloud services. This is reiterated by recital 19, which provides that the classification as digital content must be carried out regardless if such digital content is retrieved by means of downloads or online streaming. Nevertheless, recital 19 limits the openness provided by the Directive in order to classify digital content by stating that contractual agreements intended for supply of digital content that are not supplied upon physical mediums ought neither to be classified as a sale nor as a contract for services under the Directive. ${ }^{6}$

In conclusion, the Consumer Rights Directive already provides special guidelines for digital content similar to the repealed Distance Selling Directive (Directive 97/7/EC), next to provisions referring to goods sales as well as services. Pursuant to recital 19 however, contractual agreements for distribution of digital content that are not provided in physical mediums similar to contractual agreements for provision for water, gas or electricity ought to be categorized under this Directive, as either a contract for sale or as a contract for services.

Concerning their differentiation between services and the supply of digital content by the Consumer Rights Directive, a wide meaning for digital content as data that is formed and distributed within digital means may also include supply of digital products through access cloud services.

\section{Classification of Software Contracts under the USA legal system.}

\subsection{Software as A Good}

4.1.1. Article 2, Uniform Commercial Code (UCC)

This article is strictly applicable to a transaction for goods and therefore for it to be applicable, a contractual agreement ought to be related to transaction for goods. ${ }^{7}$ Hardware for computers is undoubtedly categorized as a good, therefore it is within the provisions of the Articles. However, since software is often bundled as both a physical product as well as a service, the court will still not in agreement about application of the UCC.

The movement within software transactions has been to differentiate between dominant characteristics for sale of goods as well as the accompanying service characteristic that is much more secondary to the contractual agreement. ${ }^{8}$ Even though software is an organized type of intangible, for example data, information or knowledge, it is normally vended on a physical medium, and this would debatably be considered as goods in this Article.

An argument that may give back up to this analogy would be to look at a professor's lecture. If his lectures are considered to be services are made available in book form, which is considered a good, that was utilized when considering a case about a recipe book. ${ }^{9}$

However, whether a software creates such transactions in goods will depend on some certain considerations

\footnotetext{
${ }^{1}$ Helberger/Loos/Guibault/Mak/Pessers, Digital Content Contracts for Consumers, J Consum Policy, DOI 10.1007/s10603-012-9201-1.-

${ }^{2}$ Directive 2006/123/EC of the European Parliament and of the Council of 12 December 2006 on services in the internal market.

${ }^{3}$ Helberger/Loos/Guibault/Mak/Pessers, Digital Content Contracts for Consumers, J Consum Policy, DOI 10.1007/s10603-012-9201-1.

${ }^{4}$ Schmidt-Kessel, http://www.europarl.europa.eu/document/activities/cont/201101/20110113ATT11670/20110113ATT11670EN.pdf accessed on 10th Jan 2022.

${ }_{5}^{5}$ Schmidt-Kessel, http://www.europarl.europa.eu/document/activities/cont/201101/20110113ATT11670/20110113ATT11670EN.pdf.

${ }^{6} \mathrm{Schmidt}-$ Kessel/Erler/Grimm/Kramme, Die Richtlinienvorschläge der Kommission zu Digitalen Inhalten und Online- Handel - Teil 2, in GPR 2016, p.61.

Section 2-102, UCC

${ }^{8}$ Advent Systems Ltd. V. Unisys Corp 1991

9 Ingrid Cardozo and Joseph Cardozo v. Norma True and Ellie's Book and Stationery, Inc., 342 So. 2 d 1053 (1977).
} 
such as the rights conferred to the purchaser by an agreement and where mechanisms of packaged software was established from scratch. If it is the former transaction, it requires that transactions which usually is about licenses for usage of certain software is to be deliberated as sales by this Act in the event there includes one fee providing purchasers with unlimited periods where there is a right to ownership.

In regards to the former consideration, the rational is that software that is ready-made and is nearly constantly considered as goods. Therefore, the customizing and altering standard software products is often deemed to be the production of goods rather than that of the manufacture of a service. As mentioned, software sales are often bundled with the supply of services, for example within training and practical maintenance. In the event that there's such assorted contracts for goods as well as services, it will be considered as a transaction in goods only in the event that the contract is predominantly for goods and incidentally for services. In such cases, Article 2 will simply apply when a subsidiary service is provided as the same as those that often accompany the sale of a computer system like setting up, train for use and technical support.

Therefore, if we are to assume software contracts fall under Article 2, the first query will be on whether a warranty could be part of such contractual agreements. This Article does give a definition for a warranty for contracts being express or implied. One of these could make available the foundation for breach of contracts on a developer's side. Remedies available to users are capable of being restricted by limits and disclaims a software creator could have been incorporated in the contractual agreement.

4.1.2. The Uniform Computer Information Transactions Act (UCITA)

UCITA began as a joint effort between the National Conference of Commissioners on Uniform State Laws (NCCUSL) and the American Law Institute (ALI) to integrate itself with the UCC to today's current essentials for computer and its associated goods and services. ${ }^{1}$ However, since it contains contradictory hesitations and disparities concerning important characteristics of this suggested legislation.

However, NCCUSL lost its ALI relationship the moment the institute dropped out on four years of drafting. ${ }^{2}$ Consequently, UCITA arose from the recognition of the widespread confusion software was causing ${ }^{3}$ and the need to govern computer information transactions. ${ }^{4}$ Therefore, UCITA became known as the alternate proposal fixated solely about information transactions and the inclusion of a contract involving software. ${ }^{5}$

UCITA, unlike prior legislations, gives a definition for information as well as information provided by a computer. It provides that 'data, text, images, sounds, mask works, or computer programs, including collections and compilations of them. ${ }^{6}$ While computer information is information contained in an automated manner and attained from the usage of computers or which is in a capable way of being capable of becoming processed by computers. $^{7}$

Therefore, computer information ought to be info that is electronic with the help of computers. As for defining a computer information transaction, this can be said to be agreements intended for creation, modification, transfer, or licensing of information provided by computers or the information rights contained within a computer's information. ${ }^{8}$

UCITA also gives definition for the term license. A license is defined as contracts that authorize admittance to, usage, delivery, performance, alteration, or reproduction of information and rights concerning informational, however it specifically restricts access or usage authorization or specifically awards less than all rights to information, if a transferee owns title to the licensed copy. ${ }^{9}$ In this instance, in the event a person having the rights gives away fewer than the other rights to information, a party with ownership of the rights will be measured as being granting a license to that information.

UCITA would therefore generally be applicable to software, publications made online as well as online documents, digital multimedia works, accessing contractual agreements to information across the Internet. In addition, some like transactions in which information is enclosed electronically and often needs help from computers. UCITA also makes mention of the tension between a license agreement and intellectual property law through its principles of private contract law.

The problem is whether the degree that a licensor has power over a computer's information. The Act provides that doctrines provided by private law of contract will not be able to supersede the balance provided

\footnotetext{
${ }^{1}$ Fendell. C.H \& Kennedy. D. M. (2000). UCITA Is Coming!!! Part Two: Practical Analysis for Licensors' Counsel, 17 COMPUTER LAW. 3,3 .

${ }^{2}$ Reavis. J. D \& Pogue. (2000). Controversial New Rules for Computer Contracts, tech. commentaries, p. 1

${ }^{3}$ Brennan. L. (2000). Why Article 2 Cannot Apply to Software Transactions, 38 DUQ. L. REV. 459, 461.

${ }^{4}$ Ibid

${ }^{5}$ Towle, H. K. (2011). Enough Already: It Is Time to Acknowledge that UCC Article 2 Does Not Apply to Software and Other Information, 52 S. Tex. L. Rev.531.

${ }^{6}$ Uniform Commercial Information Act (UCITA), Section 102

${ }^{7}$ Ibid

${ }^{8}$ Ibid

${ }^{9}$ Ibid
} 
nationally amid information rights holders as well as within the community. ${ }^{1}$ This therefore means that if intellectual property law makes precise indemnity to informational rights given to information rights holders, the license owner would then not be able to evade this exclusion provided under private law.

Another controversial area of software contracting that UCITA gives a mention is the concept of shrinkwrap licenses by recognizing specific circumstances where the licensee is able to contract outside customary means to demonstrating acceptance of terms.

Therefore, for shrink wrap licenses to be seen as legally binding a the licensor is required to give a licensee rights to refunds in the event that the license terms were not accessible for review up till information is bought or till the licensee conducts necessary performance. ${ }^{2}$ In addition, this legislation also legalizes different numbers of standard types of internet transactions when a licensor places a hyperlink to the terms of use be predominantly on the screen in order for a licensee to be conscious of such terms. ${ }^{3}$

In conclusion, UCITA proved to have been dedicated towards a specialized area of contract law while also addressing warranties, option for choice of law, electronically given accounts and verification, electronic agents, ownership of informational rights as well as copies, inabilities of rejecting information, accessing contracts, as well as other principles such as involuntary survival terms and procedural limitations.

However, since UCITA is solely taken into consideration for acceptance within U.S law, some scholars champion UCITA to be the principal body for the law of contract within international legislation for software since U.S companies are dominant within the software industry. Unfortunately, some scholars have also noted failure of UCITA, especially due to the reluctance of States to adopt it.

\subsection{Software as a service}

This means software becomes subjected to judicial precedence, a major characteristic provided by traditional common law rules of contract. Obligations created by a sale contract under common law include fundamental terms and conditions, warranties, time provisions as well as representation. However, for the purpose of software contracts, a few of these obligations will be discussed.

Parties subject to implied conditions are basically entitled to certain 'conditions. For example, the software seller will have the right to quiet possession as well as the right to the software at the time the contract is made, conditions that are not reciprocated under U.C.C. In addition, software subjected to common law is able to be entitled to implied warranties, unlike under protection of the U.C.C.

\section{Comparison Between the E.U And the U.S legal system of Software contract Classification}

In the US jurisdiction, courts have continuously clearly focused on tangibility as a criterion for answering the question of whether software constitutes a good. In particular, cases involving downloads show that US courts tend to abstain from using tangibility or use it only as a criterion when distinguishing between softwarehardware combination cases. ${ }^{4}$ Concerning software that is downloaded, courts tend to address the question of whether the license of software constitutes a sale and if the classification changes because software may contain intellectual property.

In order to apply UCC Article 2 warranty provisions in those cases anyway despite the intangible or intellectual property character of software, the courts have often argued by analogy or by invoking policy reasons. Especially in download cases, courts used this reasoning by analogy and held that the transaction was more likely the sale of a tangible good. UCITA, also does not refer to tangibility to define its scope. However, it does explicitly claim to also apply to goods if the main goods that have a copy (information) that is contained is a computers or computer peripherals under Section 103 (1) (a), or if giving a purchaser or the lessee of the prime goods access to usage of computer information itself becomes a material reason of the normal transaction of the kinds under UCITAs Section 103 (1) (b).

Under EU law, a similar trend away from the use of tangibility as some criteria has become evident. Early EU legislative acts such as the EU Consumer Sales Directive tend to refer to tangibility, hence, excludes intangibles such as digital products. As a result, the jurisprudence and literature regarding the application of the CISG to software revolves around tangibility, even though the statute itself does not refer to this criterion. The 2011 Consumer Rights Directive particularly focuses on the criterion of tangibility and uses it to introduce a new contract type for digital content, that is not provided on a physical item.

It also introduced explicit rules in regards to the withdrawal as well as informational duties in consumer contracts. The starting point for the development away from the criterion of tangibility in EU legislation, is taken with the latest proposal of a Digital Content Directive. In fact, the Proposal introducing contracts concerning the distribution of digital content does not use tangibility criteria. A proposed Digital Content Directive, additionally,

\footnotetext{
${ }^{1} \mathrm{Ibid}$

${ }^{2}$ UCITA, Section 112

${ }^{3}$ UCITA, Section 211

${ }^{4}$ Rottner v. AVG Techs. United States, Inc., 943 F. Supp. 2d 222, 2013
} 
claims to apply also to tangible objects which have been used solely as transporters of digital content. In cases concerning the terms 'goods' and 'services and their distinction under the EU Treaties, the CJEU has frequently used the criterion of tangibility.

The movability criterion is another distinguishing feature of goods within the EU and the US but does not lead to major problems concerning software transactions. For US cases, at least for earlier cases, movability has more significance than tangibility because movability is explicitly contained in the meaning of a good within UCC, Article 2-105, while tangibility is not mentioned in this definition of goods at all. Originally, this was reflected in the court decisions concerning software- hardware combinations where courts, if at all, looked at goods in light of their movability rather than in light of their tangibility.

However, courts in software-only cases introduced tangibility as a criteria and were rather silent on the subject of movability. In most recent download decisions, the courts moved away from the criterion of tangibility but focused on the question of whether the licensing of software precluded the application of UCC Article 2 warranty provisions. In the EU, movability, understood in a non-technical way as the ability of a product to be transferred, has rarely been addressed explicitly.

The discussion in literature, cases and legislative proposals rather, focuses at least in the past on tangibility and more recently, on the treatment of delivery provisions, the distributions of risks, as well as the rights to terminate long standing contractual agreements. As the only matter related to movability, EU legislation in both acts, the Consumer Rights Directive and in the Proposed Digital Content Directive, takes into account special features to deliver digital content. Hence, both legislative acts do not apply delivery rules towards digital content which is not delivered on physical items, or introduce specific rules regarding the requirement of delivery.

\section{Effects of Software Contracts Classification}

The United Kingdom (U.K) courts were the earliest acknowledge matters concerning electric videos in $S t$. Albans City and District Council v. International Computer Ltd. ${ }^{l}$ Here, this court treated a programmer's duty as not just a duty of skill as well as care stating that in the deficiency express terms over quality or aptness for purposes or terms. To the contrary, the contractual agreement used in transferring computer programs into a computer, envisioned by the parties to allow a computer to accomplish specific purposes, and are subjected implied terms because the program becomes sensibly appropriate for the envisioned use, that is, having reasonable capability of attaining the envisioned persistence.

Based on this precedence, legal commentators concluded that software which is transmitted electronically, with software downloads online as well, constitutes to be contracts for supplying services and therefore cannot be contracts for the sales of a goods. This decision is based on the meaning of goods in the English Sale of Goods Act of 1979. As this has been one of the prevalent ways of shedding light to the matter, the query of if the law on contracts concerning a good or a service is appropriate shed some light on matters concerning software transmitted electronically is left wide open.

In Germany, another Member, unanimity in German law today has been that software transmitted electronically is often viewed as goods and is therefore governed Section 90, German Civil Code. The German Federal Supreme Court ultimately came to this decision due to one party that wanted to purchase software. The Court began with the argument that selling software on a disk is considered as a sale of a good and because there is no physical medium, it does not in turn alter objectives of either party for obtaining the software.

Therefore, electronically transmitted software ought to be categorized similarly to software in a disk. The Federal Court additionally mentioned that electronically transmitted software distributed onto hard drives can effortlessly be moved to a tangible medium. In addition, German legal observers have arrived at the decision claiming electronically transmitted software to be goods. They have argued that a computer program ought not be considered to be different solely grounded on how it is delivered. ${ }^{2}$ Others have argued that all software are tangible goods since software that is affixed within a computer's hard drive.

Therefore, the present-day position in German Courts and legal writers is that contract law for the sale of a good is applicable to electronically transmitted software. In the United States, approaching interpretation of goods has been quite liberal. One main issue when determining contractual disputes that involve software transactions is if Article 2 of the U.C.C or common law applies. Courts recognize that Article 2 is applicable to a computer software contract is extremely important particularly concerning warranties, consequential damages, and limitations on liability. ${ }^{3}$ Nonetheless, observers seem to disagree on an answer to this query. In regards to a transaction comprising of purchasing or licensing of software with no computer hardware. Article 2 was used to adjudicate the contractual transaction. Article 2 was applied without any discussion of whether software was a good.

\footnotetext{
${ }^{1}$ St. Albans City and District Council v. International Computer Ltd. 4 All E.R. 481, 95 L.G.R. 592 , 15 Tr. L. 444 (1996).

${ }^{2}$ Diedrich. F. (1996). Maintaining Uniformity in International Uniform Law via Autonomous Interpretation: Software Contracts and the CISG, 8 Pace Int'l L. Rev. 303.

${ }^{3}$ McGonigal. (1978). Application of Uniform Commercial Code to Software Contracts, 2 Computer L. Serv. Rep. (Callaghan) 117.
} 
In the case of RRX Industries, the major shove by the courts breakdown was it holding that software sales that have a corresponding service fell under Article 2. The predominant purpose test by court was trusted to reaching a decision. This test proved that contracts containing elements of a sale of goods as well as services was categorized as per the features prevails. ${ }^{1}$

The judicial decision given in the previous case showed the United States' position when making determination for commercial contracts. It showed that the U.S courts rely on the predominant purpose test in order to decide on whether transactions of goods and services will be applicable under Article 2. The handling of transactions that do not involve sales is different within each jurisdiction. Hence, vagueness within different court decisions concerning if other cases are similar to judicial agreements generally during the application of the article towards cases involving contractual transactions that do not involve a sale.

In Addition, the type of software involved has been deemed to be relevant. A contract for the delivery of custom software is considered to be a predominant service agreement, therefore cannot be governed within Article 2, all while supplying proper standardized software could be governed by Article 2. As a consequence, having uncertainty on the kind of software that is in question may be an explanation for some of the court's decision to sometimes defer on whether the U.C.C would apply.

Agreements to develop custom software have had courts to be confronted with the question of whether a such a contract is a contractual sale of goods or a contractual service. Courts have settled that the expansion of such contracts was deemed to be a contract for service, therefore the U.C.C could not be applicable because the range of Article 2 does not give any provisions for contracts for services. Yet, the judicial system did find that it was dealing with software that was customized therefore it would not have arrived at the same decision if the software is of a standard type and sold as a mass marketed item. ${ }^{2}$ Differences amongst standardized as well as custom made software in regards to the applicability of the U.C.C is parallel to its applicability, certain courts and other commercial transactions.

A contract used for supplying and installing custom built closets was viewed as non-applicable under the U.C.C. ${ }^{3}$ In this case, the courts reason was that the predominant part of the agreement was to put in the closets and therefore that they were considered to be goods and the therefore became incidental to the contract. While arriving at this conclusion, the court noted between another case where the contractual agreement for providing and installing the school closets was found to be subjected to the U.C.C.

In that case ${ }^{4}$, the closets were deemed to be standard so it was decided that the contractual sale became a predominant aspect of the contract. Consequently, the decision that standard software is considered to be goods while software is custom made was not considered as goods but the U.C.C is not applicable to other case law concerning non-computer transactions.

American courts have also tried to combat transactions used to acquire computer hardware as well as software that involves distinct hardware and software contracts. Precedent proves that in many of the adjudicated cases, the U.C.C regarded software to be goods. However, just because courts have sometimes opted not to apply Article 2, or in circumstances where its applicability status was left undecided does not mean that there is mass confusion when opting to apply Article 2 to software transactions.

These decisions have now set a precedent with custom software where there are current laws that may not be govern within the scope of Article 2. These verdicts show that even though a few numbers of courts have come face to face with this query, the verdicts have been constant and reconcilable in the event it is seen in the commercial transactions aspect.

\section{Conclusion.}

Law on software and software contracting is definitely not about to slow down. Emerging economies such as China have now entered the software arena and this means that there is a clear need for the unification of current laws. Software contract growth in today's world proves it to be unstoppable yet the law is still lagging behind. Software contracts have clearly proved to be unique, and therefore general law of contract is not able to govern software when it is time for sale. It has proved to be difficult to try and fit software principles within the current realm of both domestic and international commercial law.

For the purposes of commercial contract law, it is important for software to be classified appropriately so as to have the appropriate choice of law. Both the United States as well as the European Union jurisdictions clearly hold similar positions. Software that is delivered upon a tangible item tends to be categorized as a good while software that is delivered through other means, such as downloading through the internet is treated as a service. The problem, however, is that the over reliance on the tangibility of software is problematic. The mode of transfer, be it electronically or through tangible items should not have any influence on categorization for

\footnotetext{
${ }^{1}$ The Goods/Services Dichotomy and the U.C.C.: Unweaving the Tangled Webb, 59 Notre Dame L. Rev. 717,719 (1984).

${ }^{2}$ Measurex Systems, Inc. v. State Tax Assessor, 490 A. 2d 1192, 1195 (Me. 1985).

${ }^{3}$ Art Metal Products Co. v. Royal Equipment Co., 670 S.W.2d 152 (Mo. Ct. App. 1984)

${ }^{4}$ Anderson Construction Co. Inc. v. Lyon Metal Products Inc. s370 So. 2d 935 (Miss. 1979)
} 
contracts involving software. This mainly is due to that even though delivery made through a tangible item, like a $\mathrm{CD}$, seems to be the enactment of goods contractual agreement, it ought not be ignored that the substance of that transaction as it being software but not the item it is delivered on.

By overlooking the mode of distribution when trying to categorize software contractual agreements, the legal aspect is forced to come face to face with actuality. Nevertheless, cases become unalike when a software product is not the main object for the purpose of a transaction and provided the software as being a part of equipment. If so, this equipment becomes the main object of this transaction other than just being the tangible item and the software ought to at least be treated as though it is a main object of the contractual agreement, where the equipment or machinery was distributed.

Therefore, with classification of contracts having more than one component, contracts for would be ruled by common law procedures of contract. This means that when determining if there is the presence of implied warranties the software will be appropriate towards the envisioned purpose will depend on affiliations amongst involved parties therefore ought to be adjudicated according to situations on a case-by-case basis. However, no help can be sought where standard software that is created for generic usage. And so, new guidelines definitely are required for the provision of implied warranties of quality. At present, the judicial thinking is that software affixed to a physical medium constitutes goods, this ends up being a major factor as to whether customs duty and taxation, important sources of income for software trading nations, are affected.

\section{References}

Brennan. L. (2000). Why Article 2 Cannot Apply to Software Transactions, 38 DUQ. L. REV. 459, 461.

CISG: TABLE OF CONTRACTING STATES, http://www.cisg.law.pace.edu/cisg/countries/cntries.html (last visited, Jan. 8, 2022).

DFC Intelligence Forecasts Global Video Game Software Industry to Reach $\$ 100$ Billion in 2018, DFC INTELLIGENCE (November 6, 2018), http://www.dfcint.com/wp/dfcintelligence-forecasts-global-videogame-software-industry-to-reach-100-billion-in-2018/. Last Visited January 8, 2022.

Diedrich. F. (1996). Maintaining Uniformity in International Uniform Law via Autonomous Interpretation: Software Contracts and the CISG, 8 Pace Int'l L. Rev. 303.

Fendell. C.H \& Kennedy. D. M. (2000). UCITA Is Coming!!! Part Two: Practical Analysis for Licensors' Counsel, 17 COMPUTER LAW. 3, 3

Helberger/Loos/Guibault/Mak/Pessers, Digital Content Contracts for Consumers, J Consum Policy, DOI 10.1007/s10603-012-9201-1.

McGonigal. (1978). Application of Uniform Commercial Code to Software Contracts, 2 Computer L. Serv. Rep. (Callaghan) 117.

Reavis. J. D \& Pogue. (2000). Controversial New Rules for Computer Contracts, tech. commentaries, p.1.

Rustad. M. L \& M.V. Onufrio. M.V. (2010). The Exportability of the Principles of Software: Lost in Translation? 2 HASTINGS SCI. AND TECH. L.J.

Schmidt-Kessel, http://www.europarl.europa.eu/document/activities/cont/201101/20110113ATT11670/20110113ATT11670 EN.pdf. (accessed on 10th Jan 2022).

Schmidt-Kessel/Erler/Grimm/Kramme, Die Richtlinienvorschläge der Kommission zu Digitalen Inhalten und Online-Handel - Teil 1, in GPR 2016, p.2.

Sein. K. (2017). What Rules Should Apply to Smart Consumer Goods? Goods with Embedded Digital Content in the Borderland Between the Digital Content Directive and 'Normal' Contract Law, 8 JIPITEC 96 para 1.

The cumulative body of EU legislation consisting of primary (EU treaties), secondary (directives and regulations) legislation and the case law of the CJEU, available https://ec.europa.eu/agriculture/glossary/acquiscommunautaire_en_de. Accessed on 9th Jan 2022.

The Goods/Services Dichotomy and the U.C.C.: Unweaving the Tangled Webb, 59 Notre Dame L. Rev. 717 , 719 (1984).

Towle, H. K. (2011). Enough Already: It Is Time to Acknowledge that UCC Article 2 Does Not Apply to Software and Other Information, 52 S. Tex. L. Rev.531. 